\title{
The Research on the Goodwill Evaluation of Exhibition Project
}

\author{
Xu Yajie ${ }^{1, a}$, li Lin ${ }^{1, b}$ \\ ${ }^{1}$ School of Management, Xi'an University of Architecture and Technology, \\ Shaanxi 710055, China; \\ a617566576@qq.com, blilin126_126@126.com,
}

Keyword: Commercial reputation of exhibition; Value appraisal; Overfulfilled profit

\begin{abstract}
With the continuous development of market economy, the goodwill attracts more people's attention, at the same time, the exhibition project goodwill has gradually become the focus of society's attention. The paper begins with the concept of exhibition project goodwill and of goodwill evaluation method analysis, proposes the use of improved income method to evaluate the goodwill value of exhibition projects.Based on this model, the value of goodwill evaluation system to make further exploration.
\end{abstract}

\section{Introduction}

Exhibition project evaluation belongs to a relatively new field in our country, while the goodwill evaluation of exhibition project is the research hot spot of experts and scholars in recent years. As the good reputation embodiment of exhibition project organizers in modern economy market, goodwill plays a vital role in the development of exhibition industry .

\section{Concept definition of exhibition project goodwill}

Definition of exhibition goodwill: exhibition goodwill refers to the intangible value formed due to the good market reputation and public reputation accumulated in history, proper organization or good service. This kind of intangible value allows the exhibition to stay in a more superior position among similar exhibitions. Therefore, the exhibition enjoys a good reputation in the participants thus possessing the ability to get excess profits. The value of this ability is just the value of the goodwill [1].

\section{Research on evaluation method of exhibition project goodwill value}

At present, there are two kinds of evaluation method for the goodwill, one being cut difference method, the other being excess return method [2]. This paper adopts improved excess return method to evaluate the goodwill value of exhibition project. We all know that the essence of goodwill value evaluation is the evaluation on excess return, while the goodwill value evaluated by cut difference method has a very great distance from the goodwill value owned by actual enterprise. Therefore, adopting the method of excess return here is relatively scientific and reasonable from viewpoints of both theory and practice.

The basic feature of goodwill is the resources which is owned or controlled by enterprises, brings excess economic benefits to the enterprises but can't be specifically identified.. Accounting Standards for Business Enterprises defines the goodwill as the ability of enterprises to obtain excess return. Excess return method is established on the view that goodwill is "The ability of enterprises to obtain excess return" [3]. Therefore, as long as an enterprise declares that it has the ability to obtain excess return, it can evaluate the goodwill. The property of goodwill determines that excess return method should be used to assess the goodwill[4]. 


\section{The establishment of goodwill evaluation model for exhibition project}

Excess return method is a method to estimate the excess return brought by the goodwill, and convert the return into present value according to certain discount rate. This method well reflects the "excess profitability", which is the essential feature of the goodwill [5]. If the excess return method is adopted, then detailed analysis and judgment should be made on total income, total cost, dynamic discount rate and the expected discount period of exhibition project goodwill, thus the goodwill evaluation value is achieved as follows:

$$
P=\sum_{i=1}^{n} R_{i} /(1+r)^{i}
$$

In the above formula: P: The goodwill value; Ri:The expected excess return brought by goodwill in year $\mathrm{i}$;: Discount rate; $\mathrm{n}$ : The expected discount period of goodwill.

\subsection{Determination of excess return}

The measurement of enterprise excess return index is mainly to determine the cardinal number of excess return by conducting sensitivity analysis on the enterprise sales income, sales cost, future investment and other factors.

Different from enterprise, exhibition project goodwill itself has its uniqueness. As to the goodwill's uniqueness, the benefits produced by exhibition project goodwill can be divided into economic and social benefits. It's ruled that:

Residual income of the exhibition project(Ri)=Total return(TR)-Total cost(TC)-

Average profit of industry(APi) $=$ Total profit(TP)-Average profit of industry(APi) (2)

Total return(TR)=Return of economy $(\mathrm{Re})+$ Return of society(Rs)

Average profit of industry $(\mathrm{APi})=$ Total $\operatorname{cost}(\mathrm{TC}) *$ Profit margin of industry average cost(I)

\subsection{Determination of dynamic discount rate}

The discount rate is the expected return on investment of capital in essence. the determination of the discount rate actually is a prediction of the future. However, there are many factors affecting our judgment in reality. The factors affecting the determination of discount rate are consistently changing. So it's said that the discount rate is not a constant value, but a dynamic value. The value of discount rate is closely linked with the expected cash flow generated by the exhibition project and the relative risk level of exhibition project as well as the opportunity cost of exhibition project. The greater the various risks facing exhibition project are, the bigger the required discount rate is. In conclusion, in the process of value assessment for exhibition project, the discount rate should be a comprehensive capital cost. The calculation formula of the model is:

$$
\text { WACC }=K_{d}(1-T) \frac{D}{V}+K_{c} \times \frac{C}{V}+K_{p} \times \frac{P}{V}+K_{r} \times \frac{R}{V}
$$

In the formula: $\quad$ Kd:Debt pre-tax capital cost; $\quad \mathrm{T}$ :Tax rate of evaluated entities; $\quad \mathrm{D}$ : Market value of active debt; $\mathrm{V}$ : Market value of evaluated entities, $(\mathrm{V}=\mathrm{D}+\mathrm{C}+\mathrm{P}+\mathrm{R})$; Kc:The market determined the equity capital cost; $\mathrm{C}$ :The market value of equity; Kp:The after-tax capital cost of preferred stock; P: Market value of preferred stock;

Kr:The capital cost of retained earnings; $\quad \mathrm{R}$ :The market value of retained earnings.

To more clearly reflect the dynamic changes of the discount rate, the project life-cycle theory is introduced here and applied flexibly to the whole process of the exhibition project. we divide the exhibition project process into early stage, growth stage, maturation stage and dissolution stage. In the early stage of exhibition project, its development is relatively slow. The development increases sharply in growth stage and maturation stage, retards until its saturation in dissolution stage. That is: 


$$
Y=\frac{-b}{(-1)^{n} a^{n}}(X-a)^{n}+b(x \geq a, y \geq b, n>0, n \neq 1)
$$

To further determine the specific time of the different stages in the project life cycle, first derivation is conducted on the equation, then second derivation is also conducted based on the above. The first derivative $\mathrm{Y}$ 'and the second derivative $\mathrm{Y}$ "of the formula are obtained respectively.

$$
\begin{aligned}
Y^{\prime} & =\frac{-n b}{(-1)^{n} a^{n}}(x-a)^{n-1} \\
Y^{\prime \prime} & =\frac{-n(n-1) b}{(-1)^{n} a^{n}}(x-a)^{n-2}
\end{aligned}
$$

According to the change of $\mathrm{Y}$ and $\mathrm{Y}$ ", the change of $\mathrm{Y}$ can be described detailedly. Thus the division of each stage is determined as follows:

\begin{tabular}{|l|l|l|l|l|}
\hline Change of Y' & Increase & Increase & Decrease & Decrease \\
\hline Change of Y” & Increase & Decrease & Decrease & Increase \\
\hline $\begin{array}{l}\text { Division of } \\
\text { stage }\end{array}$ & $\begin{array}{c}\text { Initial } \\
\text { formation }\end{array}$ & Growth & Maturation & Dissolution \\
\hline
\end{tabular}

As the divisions of project stages are determined, changes of the capital structure and changes of various capital weights in current stage and the next stage will be more obvious. Then the dynamic change of the discount rate is expressed as:

$$
\begin{aligned}
& \text { WACC }_{b+1}=\sum_{a=1}^{n} K_{a, b} W_{a, b}+\sum_{a=1}^{n} \Delta K_{a, b+1} W_{a, b+1} \\
& W_{A C C} C_{b+1}=r_{D b} \frac{D_{b}}{V_{b+1}}+r_{C b} \frac{C_{b}}{V_{b+1}}+r_{R b} \frac{R_{b}}{V_{b+1}}+r_{D b} \frac{\Delta D_{b+1}}{V_{b+1}}+r_{C b} \frac{\Delta C_{b+1}}{V_{b+1}}+r_{R b} \frac{\Delta R_{b+1}}{V_{b+1}}
\end{aligned}
$$

In the formula:b: different life cycles of exhibition project; a: different financing methods; Wa,b:weight of different financing methods ; Ka,b:individual capital cost. $\mathrm{Vb}+1=\mathrm{Vb}+\Delta \mathrm{Db}+1+\Delta \mathrm{Cb}+1+\Delta \mathrm{Rb}+1 ; \mathrm{Db}+1=\mathrm{Db}+\Delta \mathrm{Db}+1 ; \mathrm{Cb}+1=\mathrm{Cb}+\Delta \mathrm{Cb}+1 ; \quad \mathrm{Rb}+1=\mathrm{Rb}+\Delta \mathrm{Rb}+1 ;$

In the formula, $\mathrm{rDb}, \mathrm{rCb}$ or $\mathrm{rRb}$ respectively represents the individual capital cost in different stages of the project life cycle with the consideration of magnitude of risks. The calculation formula is:

$$
r=r_{f}+b \times q
$$

In the formula: rf: risk-free discount rate; b: risk factor; q: risk degree; $r$ : capital cost

\subsection{Determination of the expected discount period}

For goodwill, the determination of profit year for such open-ended intangible asset has uncertainty, and it's difficult to forecast by quantitative method. Therefore, adopting income method to calculate the profit year of exhibition project goodwill is more appropriate. Specifically speaking, key strategic plannings of the enterprise in management method, operation policy and other aspects in recent years should be provided by the top leaders of the exhibition project. Assessment\& analysis personnel conduct analysis \&consideration on asset income statement of the exhibition project and combine the opinions of all parties and the current market situation to carry on 
discussion. The return period of exhibition project goodwill is finally determined, attempting to obtain better results and make the evaluation value more fair and reasonable.

\section{Summary}

Through the study on value evaluation of exhibition goodwill in this paper, we should pay attention that the key of project goodwill evaluation also lies in determining the future economic benefits which will be brought by the goodwill. Therefore, accurately estimating the excess return of the exhibition project is the key of its value evaluation. The excess return of the exhibition project should not only consider its economic benefits, but also consider its social benefits, then the estimated value will be more scientific and comprehensive. Due to the different capital structures and risks in different stages of exhibition project life cycle, adopting dynamic discount rate to estimate the goodwill value of exhibition project is more accurate and reasonable.

\section{Reference}

[1] Li Zhiling. Humble Opinions on Exhibition Goodwill Evaluation. North and South Bridge. 2010 (3); 63-63.

[2] Zhang Tao. Goodwill Value Evaluation Research. Modern Business Trade Industry. 2011 (6); 112-112.

[3] Xiao Ai-ping. Goodwill Concept Micro Exploration. Financial Communication. 1999 (4); 13 and 14

[4] Wang Naifeng. Introduction to Self-creation Goodwill and Its Accounting Information Disclosure. Financial Research. 2006 (1); 30 and 31

[5] Chen Liyun. Accountant Processes Conception of Self-creation Goodwill. Accounting and Auditing. 2008 (7); 70-70. 